\title{
Faktor-faktor yang Berhubungan dengan Tingkat Kemandirian Activity Daily Living (ADL) pada Pasien Pasca Stroke di UPT. RSUD Undata Provinsi Sulawesi Tengah
}

\author{
Marselina $^{1}$, Finni Alfisyah* ${ }^{1}$, Hasanah $^{2}$, Muh. Jusman Rau ${ }^{1}$ \\ ${ }^{1}$ Department Epidemiology, Faculty of Public Health, Tadulako University, Palu, Indonesia \\ ${ }^{2}$ Department Nutrition, Faculty of Public Health, Tadulako University, Palu, Indonesia
}

\author{
Author's Email Correspondence (*): finnialfisyah15@yahoo.com \\ (082345511599)
}

\begin{abstract}
ABSTRAK
Stroke menyebabkan kelumpuhan hemiplegia/hemiparesis yang diakibatkan oleh kerusakan jaringan otak pada bagian berlawanan anggota tubuh. Kelumpuhan tersebut menyebabkan kecacatan pada pasien sehingga sulit untuk melakukan aktivitas dan menjadi bergantung kepada orang lain. Stroke merupakan penyebab kematian kedua dan penyebab utama kecacatan di dunia. Data Riskesdas Tahun 2018 untuk Wilayah Sulawesi Tengah mengenai prevalensi PTM menunjukkan stroke berada pada urutan ke dua dengan persentasi 10,9\%. Activity Daily Living (ADL) adalah proses rehabilitasi dengan membiasakan pasien beraktivitas secara mandiri meliputi penggunaan toilet, makan, berpakaian/berdandan dan berpindah tempat, dengan merapkan ADL membantu pasien agar cepat pulih dari ketergantungannya. Kemandirian ADL dapat terhambat jika dukungan yang diterima kurang, adanya depresi dan keparahan stroke yang diderita. Tujuan dari penelitian ini adalah untuk mengetahui tingkat kemandirian ADL pada pasien pasca stroke di UPT. RSUD Undata Provinsi Sulawesi Tengah. Jenis penelitian ini adalah kuantitatif dengan pendekatan cross sectional. Besar sampel dalam penelitian ini adalah 70 orang yang diambil melalui teknik purposive sampling. Analisis data menggunakan uji Spearman rank dengan hasil analisis variabel tingkat depresi terhadap kemandirian ADL yaitu $\rho$-value 0,000 , hasil analisis variabel dukungan keluarga terhadap kemandirian ADL yaitu $\rho$-value 0,047 , dan hasil analisis variabel jenis stroke terhadap kemandirian ADL yaitu $\rho$-value 0,524. Kesimpulan dari penelitian ini yaitu ada hubungan yang signifikan antara tingkat depresi dan dukungan keluarga terhadap kemandirian ADL pada pasien pasca stroke di UPT. RSUD Undata Provinsi Sulawesi Tengah, dan tidak ada hubungan yang signifikan antara jenis stroke yang diderita terhadap kemandirian ADL pada pasien pasca stroke di UPT. RSUD Undata Provinsi Sulawesi Tengah.
\end{abstract}

Kata Kunci: Activity Daily Living, Stroke.

Published by:

Tadulako University

Address:

Jl.Soekarno Hatta KM 9. Kota Palu, Sulawesi Tengah, Indonesia.

Phone: +628114120202

Email: Preventif.fkmuntad@gmail.com
Article history :

Received : 25082021

Received in revised form : 12122021

Accepted : 30122021

Available online 31122021 


\begin{abstract}
Stroke causes hemiplegic paralysis/hemiparesis which is caused by damage to brain tissue on the opposite side of the body. The paralysis causes disability in the patient making it difficult to carry out activities and become dependent on others. Stroke is the second leading cause of death and the leading cause of disability in the world. The 2018 Riskesdas data for the Central Sulawesi Region regarding the prevalence of NCDs shows that stroke is in second place with a percentage of $10.9 \%$. Activity Daily Living (ADL) is a rehabilitation process by familiarizing patients with independent activities including using the toilet, eating, dressing/dressing, and moving places, by applying ADL to help patients recover quickly from their dependence. ADL independence can be hampered if the support is not received by the patient, there is depression, and the severity of the stroke suffered. The purpose of this study was to determine the level of ADL independence in post-stroke patients at UPT. Undata Hospital, Central Sulawesi Province. This research was quantitative with a cross-sectional approach. It consists of 70 samples that were taken through the purposive sampling technique. The analysis shows that the $\rho$-value of the depression level on ADL independence is 0.000, the family support is 0.047, and the type of stroke suffered on ADL independence is 0.524. This research concludes that there is a significant relationship between the level of depression and family support for ADL independence, and there is no significant relationship between the types of a stroke suffered and ADL independence in post-stroke patients at Undata Regional Hospital of Central Sulawesi Province.
\end{abstract}

Keywords : Activity Daily Living, Stroke.

\title{
PENDAHULUAN
}

Frekuensi terjadinya Penyakit Tidak Menular (PTM) semakin meningkat di kalangan masyarakat. Kematian akibat PTM banyak terjadi pada negara-negara berpenghasilan rendah dan menengah, sebagian besar kematian diakibatkan oleh penyakit kardiovaskular.(1) Stroke merupakan penyakit kardiovaskular yaitu gangguan fungsional otak berupa kelumpuhan saraf atau defisit neurologis akibat adanya gangguan aliran darah menuju ke otak yang dapat muncul secara mendadak dan cepat dalam beberapa jam atau dalam beberapa detik sehingga mengakibatkan terjadinya sumbatan atau perdarahan pada salah satu bagian otak dan menyebabkan hilangnya fungsi otak bahkan adanya dampak kecacatan. Stroke dapat dibedakan menjadi dua berdasarkan penyebabnya, yaitu stroke iskemik (non perdarahan) yang terjadi akibat suplai darah ke otak terhambat atau terhenti sehingga menyebabkan terjadinya sumbatan pada pembuluh darah arteri yang mengalirkan ke otak, dan stroke hemoragik (perdarahan) yang terjadi karena perdarahan atau rusaknya pembuluh darah pada otak.(2) 
Data World Stroke Organization (WSO) menunjukkan bahwa stroke merupakan penyebab kematian kedua terbanyak di dunia dengan jumlah kematian hampir 6 juta penduduk pada tahun 2016, stroke juga merupakan penyebab utama kecacatan fisik yang terjadi pada usia produktif dan usia lanjut dengan lebih dari 13 juta kasus baru setiap tahunnya.(3) Dampak kecacatan akibat stroke yang banyak diderita pasien adalah kelumpuhan dalam bentuk hemiplegia (kelumpuhan pada satu kaki atau satu tangan bahkan satu bagian wajah) atau hemiparesis (keadaan lumpuh tapi tidak sepenuhnya pada satu kaki atau satu tangan, atau satu bagian wajah) yang dapat diakibatkan oleh jaringan otak yang rusak pada bagian berlawanan dari anggota tubuh.(4) Terdapat $40 \%$ dari 2 juta pasien stroke yang membutuhkan bantuan dalam melakukan aktivitas sehari-hari, salah satunya yaitu kelemahan bagi pasien untuk menjalani perawatan diri. Aktivitas sehari-hari atau Activity daily living (ADL) adalah proses rehabilitasi pasien stroke dalam melakukan kegiatan seharihari yang dilakukan seseorang untuk memenuhi kebutuhan hidupnya. Membiasakan pasien menerapkan ADL secara mandiri dapat membantu pasien stroke agar cepat pulih dari ketergantungannya. Penerapan ADL secara mandiri pada pasien stroke juga akan membantu mereka agar menjalani hidup dengan tidak berketergantungan dengan orang lain serta membantu proses rehabilitasi lebih cepat. Penderita stroke mengalami kelemahan dan penurunan daya tahan otot, penurunan ruang gerak, gangguan sensasi, dan masalah pada pola berjalan, hal ini menyebabkan penurunan kemampuan penderita stroke dalam pemenuhan ADL.(5)

South East Asian Medical Information Centre (SEAMIC) mengatakan bahwa angka kematian stroke terbesar di Asia Tenggara terjadi di Indonesia. Setiap tahun diperkirakan ada 500.000 penduduk yang terkena serangan stroke di Indonesia dan sekitar 25\% atau 125.000 orang meninggal, sedangkan untuk sisanya mengalami kecacatan ringan atau bahkan dapat menjadi cacat berat.(6) Data Riskesdas pada Tahun 2018 untuk Wilayah Sulawesi Tengah mengenai prevalensi PTM menunjukkan bahwa stroke berada pada urutan ke dua dengan persentasi 10,9\% setelah hipertensi $(34,1 \%) .(7)$ Kemudian berdasarkan studi pendahuluan yang dilakukan di UPT. RSUD Undata Provinsi Sulawesi Tengah yang menjadi pusat rujukan utama di Kota Palu terdapat kesenjangan jumlah penderita stroke dari tahun 2018 dengan jumlah 117 pasien, mengalami peningkatan menjadi 187 pasien pada tahun 2019, kemudian pada tahun 2020 mengalami penurunan yaitu menjadi 151 pasien. Terlihat bahwa tejadi kecenderungan yang menyebabkan meningkatnya jumlah kasus penderita stroke 
diakibatkan karena adanya transisi demografi dan teknologi di Indonesia yang menyebabkan perubahan pola PTM stroke yang sebelumnya didominasi oleh orang tua yang berusia di atas 50 tahun ke atas, namum sekarang juga dapat menyerang pasien di bawah 50 tahun bahkan pada kalangan remaja.(8)

Pasien stroke akan kesulitan atau bahkan tidak bisa beradaptasi dengan baik terhadap kondisi dan dampak negatif dari serangan stroke, banyaknya keterbatasan dalam melakukan aktivitas juga mendorong pasien berpikir bahwa hidupnya selalu bergantung pada orang lain dan merasa tidak berguna. Depresi yang dibiarkan akan menghambat pasien dalam melakukan ADL. Dukungan Keluarga berperan penting dalam meningkatkan kemandirian ADL, hal ini dikarenakan keluarga merupakan kerabat terdekat pasien. Dukungan keluarga yang bersifat positif seperti memberikan motivasi, saran, meluangkan waktu dan juga membantu pengobatan pasien akan menumbuhkan rasa percaya diri dan keyakinan akan sembuh, dukungan yang positif juga akan membantu menumbuhkan semangat pada pasien untuk terus berlatih. Saat pertama mengalamai stroke, kemandirian ADL pada pasien stroke hemoragik dan pasien stroke iskemik keduanya berada pada kategori ketergantungan total, hal ini dikarenakan dampak berupa kelumpuhan motorik dan penurunan kesadaran yang merupakan dampak terbesar yang disebabkan oleh stroke. Perburukan kondisi pasien terparah terjadi pada jenis stroke hemoragik, dengan perburukan kondisi tubuh yang parah maka akan menghambat pasien dalam melakukan ADL. Tujuan penelitian ini adalah untuk mengetahui faktor-faktor yang berhubungan dengan kemandirian pasien pasca stroke dalam melakukan activity daily living (ADL) pasien pasca stroke di UPT. RSUD Undata Provinsi Sulawesi Tengah.

\section{METODE}

Penelitian ini merupakan penelitian kuantitatif dengan menggunakan pendekatan observasional analitik dengan desain cross sectional study. Metode Kuantitatif digunakan sebagai metode untuk meneliti populasi atau sampel tertentu, pengumpulan data menggunakan instrumen penelitian berupa kuesioner. Kemandirian ADL diukur menggunakan Bather Index dan depresi diukur menggunakan Hamilton Depression Rating Scale (HDRS). Analisis data bersifat statistic, dengan tujuan untuk menguji hipotesis yang telah ditetapkan. Variabel dependen dalam penelitian ini adalah tingkat kemandirian ADL pasien pasca stroke sedangkan variabel independen adalah tingkat depresi, dukungan 
keluarga dan jenis stroke yang diderita. Lokasi pada penelitian ini dilaksanakan di UPT. RSUD Undata Provinsi Sulawesi Tengah dengan waktu penelitian yaitu dimulai pada tanggal 04 November s.d 28 Desember tahun 2020. Populasi pada penelitian ini yaitu pasien pasca stroke yang pernah mendapatkan perawatan baik rawat inap maupun rawat jalan di UPT. RSUD Undata Provinsi Sulawesi Tengah yaitu sebanyak 154 pasien dengan teknik pengambilan sampel menggunakan purposive sampling dengan kriteria inklusi pasien stroke rawat jalan maupun rawat inap di UPT. RSUD. Undata Palu Provinsi Sulawesi Tengah, berdomisili di Kota Palu, responden dapat berkomunikasi dengan baik., dan kriteria eksklusi yaitu responden merupakan pasien rujukan dari luar Kota Palu. Analisis data dilakukan menggunakan 2 cara yaitu analisis univariat untuk menggambarkan karateristik sampel responden, serta variabel independen yaitu depresi, dukungan keluarga dan jenis stroke yang diderita dan variabel dependen yaitu tingkat kemandirian Activity Daily Living (ADL) pasien pasca stroke. Kedua yaitu analisis bivariat untuk mengetahui kuatnya hubungan dan arah hubungan antara variabel dependen dengan variabel independen. Pada penelitian ini, untuk mengatahui faktor-faktor yang berhubungan dengan Activity Daily Living (ADL) menggunakan uji hipotesis Spearman rank.

\section{HASIL}

\section{Analisis Univariat}

Analisis univariat bertujuan untuk menggambarkan distribusi frekuensi masingmasing variabel, baik variabel bebas, variabel terikat, maupun deskripsi karakteristik responden, sebagai berikut:

\section{Umur}

Distribusi responden menurut umur pada penelitian ini dapat dilihat pada tabel 1 sebagai berikut:

Tabel 1

Distribusi Frekuensi Umur Responden

\begin{tabular}{ccc}
\hline Umur Responden & $\mathbf{n}$ & $\mathbf{( \% )}$ \\
\hline $17-25$ tahun & 2 & 2,9 \\
$26-35$ tahun & 10 & 14,3 \\
$36-45$ tahun & 16 & 22,9 \\
$46-55$ tahun & 25 & 35,7 \\
$56-65$ tahun & 11 & 15,7 \\
$>65$ tahun & 6 & 8,6 \\
\hline Total & $\mathbf{7 0}$ & $\mathbf{1 0 0} \%$ \\
\hline
\end{tabular}

Sumber: Data Primer, 2020 
Berdasarkan tabel 1 menunjukkan bahwa dari 70 responden, kelompok umur yang menjadi responden terbanyak yaitu 45-55 tahun dengan jumlah 25 responden $(35,7 \%)$ dan terendah berada pada kelompok umur 17-25 tahun dengan jumlah 2 responden $(2,9 \%)$.

\section{Jenis Kelamin}

Distribusi responden menurut jenis kelamin pada penelitian ini dapat dilihat pada tabel 2 sebagai berikut:

Tabel 2

Distribusi Frekuensi Jenis Kelamin Responden

\begin{tabular}{ccc}
\hline $\begin{array}{c}\text { Jenis Kelamin } \\
\text { Responden }\end{array}$ & $\mathbf{n}$ & $\mathbf{( \% )}$ \\
\hline Laki-laki & 45 & 64,3 \\
Perempuan & 25 & 35,7 \\
\hline Total & $\mathbf{7 0}$ & $\mathbf{1 0 0}$ \\
\hline Sumber: Data Primer, 2020 & &
\end{tabular}

Sumber: Data Primer, 2020

Berdasarkan tabel 2 menunjukkan bahwa dari 70 responden, responden terbanyak berada pada kategori jenis kelamin laki-laki dengan jumlah 45 responden (64,3\%), sedangkan pada kategori jenis kelamin perempuan berjumlah 25 responden $(35,7 \%)$.

\section{Kemandirian Activiry Daily Living (ADL)}

Distribusi responden menurut kemandirian ADL pada penelitian ini dapat dilihat pada tabel 3 sebagai berikut:

Tabel 3

Distribusi Frekuensi Kemandirian ADL Responden

\begin{tabular}{ccc}
\hline $\begin{array}{c}\text { Kemandirian ADL } \\
\text { Responden }\end{array}$ & n & $\mathbf{( \% )}$ \\
\hline Tidak Mandiri & 60 & 85,7 \\
Mandiri & 10 & 14,3 \\
\hline Total & $\mathbf{7 0}$ & $\mathbf{1 0 0} \%$ \\
\hline
\end{tabular}

Sumber: Data Primer, 2020

Berdasarkan tabel 3 menunjukkan bahwa dari 70 responden, responden terbanyak berada pada kategori tidak mandiri dengan jumlah 60 responden $(85,7 \%)$, sedangkan pada kategori mandiri berjumlah 10 responden $(14,3 \%)$.

\section{Tingkat Depresi}


Distribusi responden menurut tingkat depresi pada penelitian ini dapat dilihat pada tabel 5.4 sebagai berikut:

Tabel 4

Distribusi Frekuensi Tingkat Depresi Responden

\begin{tabular}{ccc}
\hline $\begin{array}{c}\text { Tingkat Depresi } \\
\text { Responden }\end{array}$ & $\mathbf{n}$ & $\mathbf{( \% )}$ \\
\hline Normal & 5 & 7,1 \\
Ringan & 8 & 11,4 \\
Sedang & 15 & 21,4 \\
Berat & 42 & 60,0 \\
\hline Total & $\mathbf{7 0}$ & $\mathbf{1 0 0} \%$
\end{tabular}

Sumber: Data Sekunder, 2020

Berdasarkan tabel 4 menunjukkan bahwa dari 70 responden, tingkat depresi terbanyak yang dialami responden berada pada ketegori depresi berat dengan jumlah 42 responden $(60,0 \%)$, sedangkan terendah pada kategori normal dengan jumlah 5 responden $(7,1 \%)$.

\section{Dukungan Keluarga}

Distribusi responden menurut dukungan keluarga pada penelitian ini dapat dilihat pada tabel 5 sebagai berikut:

Tabel 5

Distribusi Frekuensi Dukungan Keluarga Responden

\begin{tabular}{ccc}
\hline $\begin{array}{c}\text { Dukungan } \\
\text { Keluarga Responden }\end{array}$ & $\mathbf{n}$ & $\mathbf{( \% )}$ \\
\hline Rendah & 4 & 5,7 \\
Sedang & 14 & 20,0 \\
Tinggi & 52 & 74,3 \\
\hline Total & $\mathbf{7 0}$ & $\mathbf{1 0 0}$ \\
\hline
\end{tabular}

Sumber: Data Primer, 2020

Berdasarkan tabel 5 menunjukkan bahwa dari 70 responden, kelompok dukungan keluarga terbanyak berada pada kategori dukungan keluarga tinggi dengan jumlah 52 responden $(74,3 \%)$, sedangkan kelompok dukungan keluarga terendah berada pada kelompok dukungan keluarga rendah dengan jumlah 4 responden $(5,7 \%)$.

\section{Jenis Stroke}

Distribusi responden menurut jenis stroke yang diderita pada penelitian ini dapat dilihat pada tabel 6 sebagai berikut: 
Tabel 6

Distribusi Frekuensi Jenis Stroke Responden

\begin{tabular}{ccc}
\hline $\begin{array}{c}\text { Jenis Stroke } \\
\text { Responden }\end{array}$ & N & $(\boldsymbol{\%})$ \\
\hline Hemoragik & 13 & 18,6 \\
Iskemik & 57 & 81,4 \\
\hline Total & $\mathbf{7 0}$ & $\mathbf{1 0 0} \%$ \\
\hline
\end{tabular}

Sumber: Data Sekunder, 2019

Berdasarkan tabel 6 menunjukkan bahwa dari 70 responden, responden terbanyak pada kategori jenis stroke iskemik dengan jumlah 57 responden $(81,4 \%)$, sedangkan pada kategori jenis stroke hemoragik berjumlah 13 responden $(18,6 \%)$.

\section{Analisis Bivariat}

Analisis dilakukan menggunakan Uji korelasi Spearman rank. Ketentuan uji adalah H0 diterima jika $p$-value lebih dari 0,05 dan $\mathrm{H} 0$ ditolak jika $p$-value kurang atau sama dengan 0,05 Selengkapnya hasil uji Spearman rank masing-masing variabel independent terhadap dependent ditampilkan pada tabel sebagai berikut:

\section{Hubungan Tingkat Depresi dengan Kemandirian Activity Daily Living (ADL)}

Adapun hubungan tingkat depresi dengan kemandirian ADL pada pasien pasca stroke di UPT. RSUD Undata Provinsi Sulawesi Tengah dalam penelitian ini disajikan pada tabel 7 sebagai berikut:

Tabel 7

Analisis Hubungan Tingkat Depresi dengan Kemandirian Activity Daily Living (ADL) Pasen Pasca Stroke di UPT. RSUD Undata Provinsi Sulawesi Tengah Tahun 2019

\begin{tabular}{|c|c|c|c|c|c|c|c|c|}
\hline \multirow{3}{*}{$\begin{array}{l}\text { Tingkat } \\
\text { Depresi }\end{array}$} & \multicolumn{4}{|c|}{ Kemandirian ADL } & \multirow{2}{*}{\multicolumn{2}{|c|}{ Total }} & \multirow{3}{*}{$\begin{array}{c}\text { pvalu } \\
e\end{array}$} & \multirow{3}{*}{ rhitung } \\
\hline & \multicolumn{2}{|c|}{$\begin{array}{c}\text { Tidak } \\
\text { Mandiri }\end{array}$} & \multicolumn{2}{|c|}{ Mandiri } & & & & \\
\hline & n & $\%$ & $\mathbf{n}$ & $\%$ & $\mathbf{N}$ & $\%$ & & \\
\hline Normal & 0 & 0 & 5 & 7,1 & 5 & 7,1 & & \\
\hline Ringan & 3 & 4,3 & 5 & 7,1 & 8 & 11,4 & & \\
\hline Sedang & 15 & 21,4 & 0 & 0 & 15 & 21,4 & 0,000 & 0,672 \\
\hline Berat & 42 & 60 & 0 & 0 & 42 & 60 & & \\
\hline Total & 60 & 86,7 & 10 & 14,3 & 70 & 100 & & \\
\hline
\end{tabular}

Berdasarkan tabel 7, menunjukkan bahwa dari 5 pasien dengan tingkat depresi normal, semua berada pada kategori mandiri dalam melakukan ADL $(7,1 \%)$, dan dari 42 responden 
dengan tingkat depresi berat semua berada pada kategori tidak mandiri dalam melakukan ADL (60\%).

\section{Hubungan Dukungan Keluarga dengan Kemandirian Activity Daily Living (ADL)}

Adapun hubungan dukungan keluarga dengan kemandirian ADL pada pasien pasca stroke di UPT. RSUD Undata Provinsi Sulawesi Tengah dalam penelitian ini disajikan pada tabel 8 sebagai berikut:

\section{Tabel 8}

Analisis Hubungan Dukungan Keluarga dengan Kemandirian Activity Daily Living (ADL) Pasien Pasca Stroke di UPT. RSUD Undata Provinsi Sulawesi Tengah Tahun 2019

\begin{tabular}{|c|c|c|c|c|c|c|c|c|}
\hline \multirow{3}{*}{$\begin{array}{l}\text { Dukunga } \\
\text { n } \\
\text { Keluarga }\end{array}$} & \multicolumn{4}{|c|}{ Kemandirian ADL } & \multirow{2}{*}{\multicolumn{2}{|c|}{ Total }} & \multirow{3}{*}{ pvalue } & \multirow{3}{*}{$\begin{array}{c}\text { mitun } \\
\mathbf{g}\end{array}$} \\
\hline & \multicolumn{2}{|c|}{$\begin{array}{c}\text { Tidak } \\
\text { Mandiri }\end{array}$} & \multicolumn{2}{|c|}{ Mandiri } & & & & \\
\hline & $\mathbf{N}$ & $\%$ & $\mathbf{n}$ & $\%$ & $\mathbf{N}$ & $\%$ & & \\
\hline Rendah & 4 & 5,7 & 0 & 0 & 4 & 5,7 & & \\
\hline Sedang & 14 & 20 & 0 & 0 & $\begin{array}{l}1 \\
4\end{array}$ & 20 & & \\
\hline Tinggi & 42 & 60 & $\begin{array}{l}1 \\
0\end{array}$ & $\begin{array}{c}14, \\
3\end{array}$ & $\begin{array}{l}5 \\
2\end{array}$ & $\begin{array}{c}74 \\
3\end{array}$ & 0,047 & 0,238 \\
\hline Total & 60 & 85,7 & $\begin{array}{l}\mathbf{1} \\
\mathbf{0}\end{array}$ & $\begin{array}{c}14, \\
3\end{array}$ & $\begin{array}{l}7 \\
0\end{array}$ & 100 & & \\
\hline
\end{tabular}

Berdasarkan tabel Berdasarkan tabel 8, menunjukkan bahwa dari 4 pasien dengan dukungan keluarga rendah, semua berada pada kategori tidak mandiri dalam melakukan ADL $(5,7 \%)$, dan dari 52 responden dengan dukungan keluarga tinggi sebanyak 42 responden berada pada kategori tidak mandiri dalam melakukan ADL (60\%) dan sebanyak 10 responden berada pada kategori mandiri $(14,3)$.

\section{Hubungan Jenis Stroke dengan Kemandirian Activity Daily Living (ADL)}

Adapun hubungan jenis stroke yang diderita dengan kemandirian ADL pada pasien pasca stroke di UPT. RSUD Undata Provinsi Sulawesi Tengah dalam penelitian ini disajikan pada tabel 9 sebagai berikut: 
Tabel 9

Analisis Hubungan Jenis Stroke dengan Kemandirian Activity Daily Living (ADL) Pasien Pasca Stroke di UPT. RSUD Undata Provinsi Sulawesi Tengah Tahun 2019

\begin{tabular}{|c|c|c|c|c|c|c|c|c|}
\hline \multirow{3}{*}{ Jenis Stroke } & \multicolumn{4}{|c|}{ Kemandirian ADL } & \multirow{2}{*}{\multicolumn{2}{|c|}{ Total }} & \multirow{3}{*}{$\begin{array}{c}\text { p.valu } \\
e\end{array}$} & \multirow{3}{*}{ rhitung } \\
\hline & \multicolumn{2}{|c|}{$\begin{array}{c}\text { Tidak } \\
\text { Mandiri }\end{array}$} & \multicolumn{2}{|c|}{ Mandiri } & & & & \\
\hline & $\bar{n}$ & $\%$ & $\mathbf{n}$ & $\%$ & $\mathbf{N}$ & $\%$ & & \\
\hline Hemoragik & 13 & 18,6 & 0 & 0 & $\begin{array}{l}1 \\
3\end{array}$ & $\begin{array}{c}18, \\
6\end{array}$ & 0,524 & 0,077 \\
\hline Iskemik & 47 & 67,1 & 10 & $\begin{array}{c}14, \\
3\end{array}$ & $\begin{array}{l}5 \\
7\end{array}$ & $\begin{array}{c}81, \\
4\end{array}$ & & \\
\hline Total & 60 & 85,7 & 10 & $\begin{array}{c}14, \\
3\end{array}$ & $\begin{array}{l}7 \\
0\end{array}$ & 100 & & \\
\hline
\end{tabular}

Berdasarkan tabel Berdasarkan tabel 9 menunjukkan bahwa dari 13 pasien dengan jenis stroke hemoragik, semua berada pada kategori tidak mandiri dalam melakukan ADL $(18,6 \%)$, dan dari 57 responden dengan jenis stroke iskemik sebanyak 47 responden berada pada kategori tidak mandiri dalam melakukan ADL $(67,1 \%)$ dan sebanyak 10 responden berada pada kategori mandiri $(14,3)$.

\section{PEMBAHASAN}

\section{Hubungan Tingkat Depresi dengan Kemandirian Activity Daily Living (ADL)}

Berdasarkan hasil dari penelitian yang dilakukan pada tabel 7 menunjukkan bahwa dari 70 responden, 5 responden memiliki tingkat depresi yang normal $(7,1 \%), 8$ responden memiliki tingkat depresi yang ringan $(11,4 \%), 15$ responden memiliki tingkat depresi yang sedang $(21,4 \%)$ dan 42 responden memiliki tingkat depresi yang berat $(60 \%)$. Berdasarkan hasil penelitian terlihat bahwa kebanyakan responden memiliki tingkat depresi yang berat, banyak responden yang ditemukan sulit atau belum bisa beradaptasi dengan baik setelah tubuhnya terkena stroke, banyaknya keterbatasan dalam melakukan aktivitas juga mendorong pasien berpikir bahwa hidupnya selalu bergantung pada orang lain dan merasa tidak berguna. Hal-hal tersebut akan semakin meningkatkan depresi pada pasien pasca stroke, banyak responden ditemukan sulit dalam mengendalikan emosi yang dikarenakan tidak adanya perkembangan kondisi yang lebih baik dan merasa sulit untuk mengungkapkannya. Pemberian semangat dan dukungan dari lingkungan sekitar juga akan bermanfaat untuk membantu menumbuhkan rasa percaya diri dan membantu agar pasien tidak merasa murung 
sehingga pasien dapat yakin bahwa dapat melalui semua masa-masa sulit tersebut. Penanggulangan depresi secara cepat dan tepat pada pasien pasca stroke merupakan intervensi penting yang dapat membantu pasien untuk mengelola stres pada dirinya, hal tersebut akan lebih membantu pasien untuk lebih berpikir positif mengenai penyakit yang dideritanya, membantu pasien agar tidak berburuk sangka pada dirinya sendiri atau bahkan pada orang lain. Penanggulangan depresi dapat dilakukan yaitu berupa terapi, ada beberapa jenis terapi yang dapat diberikan kepada pasien pasca stroke yaitu:

1. Electroconvulsive therapy (ECT), terapi ini menggunakan alat kejut listrik yang dialirkan ke tubuh pasien. Terapi ini digunakan sebagai terapi untuk depresi berat apabila gagal dengan terapi antidepresan atau terapi obat.

2. Transcranial magnetic stimulation (TMS), TMS adalah sebuah proses yang menggunakan medan magnet yang dapat menstimulasi sel saraf otak untuk menyembuhkan depresi.

3. Psikoterapi yang ditujukan kepada individu atau pada setiap pasien berdasarkan problem masing-masing untuk mengobati depresi pada pasien.

4. Cognitive behavioral therapy (CBT), terapi ini digunakan untuk pasien dengan disfungsi pikiran atau kepercayaan yang berhubungan dengan mood yang rendah dan membangun lebih banyak kepercayaan pada pasien.

5. Motivational interviewing, yaitu bentuk pemberian bimbingan yang bersifat kolaborasi dengan tujuan untuk memperkuat motivasi pada pasien.

6. Community based groups/support groups, yaitu terapi kelompok untuk mengurangi kesendirian dan mendorong hubungan interpersonal.

7. Terapi musik, yaitu intervensi terapi berupa mendengarkan musik dalam kelompok, pergerakan tubuh dan melukis dengan disertai improvisasi menyanyi.

8. Ecosystem focused therapy (EFT), yaitu intervensi yang bertujuan meningkatkan kemapuan pasien depresi pasca stroke untuk melakukan sosialisasi yang besar.

9. Akupuntur

10. Pemberian latihan fisik dan Latihan beradaptasi.

Hasil analisis uji spearman rank tingkat depresi terhadap kemandirian ADL pada pasien pasca stroke di UPT. RSUD Undata Provinsi Sulawesi Tengah menunjukkan bahwa nilai $p$-value $=0,000$ dengan, karena nilai $p$-value $<0,05$, maka artinya terdapat hubungan signifikan antara variabel tingkat depresi terhadap kemandirian ADL, kemudian analisis berdasarkan kuat hubungan dengan nilai -0,672 maka dapat dikatakan terjadi hubungan yang 
kuat antara tingkat depresi terhadap kemandirian ADL, dan analisis berdasarkan arah hubungan menunjukkan nilai negatif, maka hubungan kedua variabel tidak searah yang berarti jika variabel tingkat depresi meningkat maka variabel kemandirian ADL akan menurun.

Hasil penelitian ini sejalan dengan Chemerinski E, Robinson RG, Kosier JT, yang mengatakan bahwa ada hubungan yang signifikan antara tingkat depresi terhadap kemandirian ADL. Pasien yang mengalami penurunan tingkat depresi sejak awal mengalami stroke menunjukkan peningkatan yang baik terhadap kemandirian ADL dibandingkan dengan

pasien dengan tingkat depresi yang mengalami penurunan. Penanggulangan depresi secara cepat dam tepat pada pasien pasca stroke memiliki efek yang positif pada hasil rehabilitasi, dimana akan membuat pasien tidak mudah berburuk sangka pada penyakit dan dirinya sendiri, atau bahkan pada orang lain. Pasien akan lebih berpikir dengan jernih dan menjalani masa rehabilitasi dengan nyaman.(9)

Hasil penelitian ini juga sejalan dengan Haghgoo HA, Pazuki ES, Hosseini AS, Rassafiani M, yang mengatakan bahwa ada hubungan yang signifikan antara tingkat depresi dengan kemandirian ADL pasien pasca stroke. Pasien stroke memiliki masalah fisik dan psikis yang buruk pada awal serangan stroke terjadi yang menyebabkan pasien membutuhkan waktu untuk beradaptasi dengan tubuhnya setelah terkena stroke. Ketakukan yang dimiliki pasien pasca stroke yang berlebihan juga akan menghambat pasien menjadi mandiri, pasien menjadi takut untuk berlatih dikarenakan pernah terjatuh saat sedang berlatih terutama saat berlatih berjalan.(10)

Perubahan fisik, mental maupun emosional pada pasien stroke akan menghambat kemandirian dalam melakukan ADL. Adanya perasaan tidak nyaman yang dirasakan oleh pasien akan sangat mengganggu dan menjadi tidak tertarik dalam berlatih. Adanya penolakan diri terhadap fisiknya yang baru juga akan membuat pasien menjadi depresi. Pasien yang tidak terbiasa akan dampak kecacatan yang diakibatkan oleh stroke akan sulit menerima kondisinya yang baru, adaptasi yang dilakukan pasien tidak selalu berhasil dan tidak mudah untuk dilakukan, sehingga banyak ditemukan adanya pasien stroke yang memiliki tingkat depresi yang tinggi.(11)

\section{Hubungan Dukungan Keluarga dengan Kemandirian Activity Daily Living (ADL)}

Berdasarkan hasil penelitian pada tabel 8 menunjukkan bahwa dari 70 responden, jumlah responden yang memiliki dukungan keluarga rendah yaitu 4 orang $(5,7 \%)$, reponden 
dengan dukungan keluarga sedang yaitu 14 orang (20\%) dan responden dengan dukungan keluarga rendah yaitu 52 orang $(74,3 \%)$. Berdasarkan hasil penelitian, sebagian besar responden memiliki dukungan keluarga yang tinggi, namun banyak ditemukan keluarga yang memberikan dukungan informasi/pengetahuan yang kurang untuk pasien. Informasi/pengetahuan yang didapatkan keluarga mengenai penyakit pasien masih sangat rendah sehingga menyebabkan rendahnya dukungan keluarga yang diberikan, khususnya dukungan dalam bentuk informasi/pengetahuan mengenai penyakit yang diderita pasien. Keluarga tidak memiliki informasi atau pengetahuan yang mencukupi agar bisa menghimbau pasien untuk tidak melakukan hal yang dapat memperburuk keadaan pasien. Pemberian dukungan yang bernilai positif khususnya yang berasal dari keluarga merupakan jenis dukungan yang terbesar karena keluarga marupakan kerabat terdekat dari pasien, oleh karena itu keluarga sangat diharapkan agar selalu mendampingi dan berusaha memberikan peran yang maksimal dalam upaya kesembuhan pasien, dengan adanya dukungan dari keluarga akan membantu pasien untuk menumbuhkan rasa percaya diri dan keyakinan akan sembuh, dukungan yang positif juga akan membantu menumbuhkan semangat pada pasien untuk terus berlatih.

Dukungan keluarga yang baik yaitu dukungan yang memenuhi 4 aspek yaitu dukungan instrumental, dukungan informasi, dukungan emosional dan juga dukungan penghargaan.(12) Aspek dukungan instrumental dapat berupa transportasi, biaya berobat dan juga fasilitas yang diberikan keluarga pada pasien. dukungan keluarga yang diberikan dalam aspek ini dapat berbeda-beda dilihat dari hubungan kedekatan pasien dengan anggota keluarga lain, sering atau tidaknya berkomunikasi, sumber daya keuangan dan juga peran gender. Peran gender yang dimaksud yaitu dimana wanita lebih dominan membantu dalam hal sarana dan peralatan pasien, sedangkan pria lebih berperan dalam hal membantu pembiayaan dan transportasi untuk berobat pasien.(13) Aspek dukungan informasi dipengaruhi oleh informasi/pengetahuan yang didapatkan keluarga mengenai penyakit yang diderita pasien sangat rendah, rendahnya informasi/pengetahuan yang didapatkan akan mempengaruhi dukungan yang diberikan oleh keluarga kepada pasien, semakin rendah informasi dan pengetahuan yang diperoleh keluarga maka dukungan keluarga dalam aspek dukungan informasi juga akan rendah.(14) Aspek dukungan emosional yaitu dimana menempatkan keluarga sebagai tempat yang aman dan nyaman untuk pemulihan dan membantu penguasaan emosi. Penanaman kepercayaan, perhatian, mendengarkan dan didengarkan adalah aspek dari dukungan ini. Aspek dukungan penghargaan yang rendah 
disebabkan olehnya perasaan yang tidak nyaman dalam keluarga dikarenakan tidak terbiasa mengungkapkan. Dukungan ini dapat berupa pujian atau motivasi yang dapat membesarkan hati pasien untuk terus berlatih dalam proses rehabilitasi.(12)

Hasil analisis uji spearman rank, dukungan keluarga terhadap kemandirian ADL pada penderita stroke di UPT. RSUD Undata Provinsi Sulawesi Tengah menunjukkan nilai $p$-value $=0,047$, karena nilai $p$-value $<0,05$ maka $\mathrm{H} 0$ pada penelitian ini ditolak, artinya terdapat hubungan signifikan antara variabel dukungan keluarga terhadap kemandirian ADL

pada pasien pasca stroke di UPT. RSUD Undata Provinsi Sulawesi Tengah, kemudian analisis berdasarkan kuat hubungan dengan nilai 0,238 maka dapat dikatakan terjadi hubungan yang sangat lemah antara dukungan keluarga terhadap kemandirian ADL, hal ini dikarenakan masih banyak responden dengan dukungan keluarga yang tinggi tetapi berada pada kategori tidak mandiri. Analisis berdasarkan arah hubungan menunjukkan nilai positif, maka hubungan kedua variabel dikatakan searah yang berarti jika variabel dukungan keluarga meningkat maka variabel kemandirian ADL juga meningkat. Dukungan keluarga sangat penting dan merupakan harapan bagi penderita stroke. Adanya dukungan yang keluarga yang tinggi dan bersifat positif maka akan sangat membantu pasien untuk terus berlatih agar menjadi mandiri, selain itu dukungan keluarga juga membuat pasien agar memiliki hati yang besar sehingga tidak mudah menyerah.

Penelitian ini sejalan dengan Mant J, Carter J, Wade DT, Winner S yang mengatakan ada hubungan yang signifikan antara dukungan keluarga terhadap kemandirian ADL pasien pasca stroke. Dukungan keluarga yang bersifat positif dapat meningkatkan kemandirian pasien pasca stroke, hal ini dikarenakan karena energi positif yang diberikan oleh keluarga kepada pasien akan berdampak pada tumbuhnya dorongan yang besar yang diterima pasien, sehingga akan membuat pasien terus semangat dalam berlatih agar dapat mandiri.(15)

Dukungan keluarga akan dapat membantu proses perawatan pasien stroke agar dapat melakukan aktivitas kembali meskipun tidak sepenuhnya kembali normal. Adanya dukungan keluarga yang optimal, akan menyebabkan pasien stroke menjadi mandiri dalam melakukan aktivitas dan apabila tidak ada dukungan keluarga maka pasien stroke menjadi ketergantungan kepada orang lain dalam pemenuhan ADL.(12)

Penelitian ini juga sejalan dengan Mayasari D, Imanto M, Larasati T, Ningtiyas IF yang mengatakan ada hubungan signifikan antara dukungan keluarga terhadap kemandirian ADL pasien pasca stroke. Pasien pasca stroke harus didukung dari pihak keluarga maupun 
lingkungan sekitar untuk terus memberikan semangat agar lekas sembuh dan kembali dalam keadaan seperti semula.(5)

Kejadian stroke dapat menimbulkan kelemahan dalam kehidupan sehari-hari. Salah satunya adalah ketidakmampuan perawatan diri akibat kelemahan pada ekstremitas dan penurunan fungsi mobilitas yang dapat menghambat kemandirian ADL. Peran keluarga bagi pasien stroke sangat beragam, diantaranya yaitu selalu membantu dan memberikan motivasi

pada pasien, dimana tubuh pasien yang tidak lagi dapat bekerja dengan normal sehingga membutuhkan seseorang untuk terus membantu dalam beraktivitas dan juga berlatih.(5)

\section{Hubungan Jenis Stroke dengan Kemandirian Activity Daily Living (ADL)}

Berdasarkan hasil penelitian yang dilakukan pada tabel 9 menunjukkan bahwa dari 70 responden, lebih banyak berada pada kelompok jenis stroke iskemik dengan jumlah 57 responden $(81,4 \%)$, sedangkan responden yang pada kelompok jenis stroke hemoragik memiliki berjumlah 13 responden $(18,6 \%)$. Hasil dari penelitian yang dilakukan pada variabel jenis stroke terlihat bahwa responden dengan jenis stroke hemoragik semuanya berada pada ketegori tidak mandiri, hal ini dikarenakan perburukan kondisi yang lebih parah dibandingkan dengan stroke iskemik sehingga membuat pasien akan lebih bergantung pada orang lain dalam melakukan aktivitas sehari-hari sehingga membuat pasien menjadi tidak mandiri dalam melakukan ADL, namun hal ini tidak menutup kemungkinan adanya responden yang tidak mandiri pada jenis stroke iskemik, terbukti pada saat penelitian ditemukan responden dengan jenis stroke iskemik yang memiliki skor kemandirian yang rendah, hal ini disebabkan oleh faktor usia responden, adanya depresi yang berat dan juga dukungan keluarga yang kurang. Penanganan yang segera dan dilakukan dengan tepat yang sesuai dengan keadaan pasien yang harus dilakukan secara menyeluruh mengenai komplikasi dan kondisi penyakit yang terjadi pada pasien merupakan cara untuk mengurangi atau membatasi terjadinya kecacatan, bahkan mencegah sehingga tidak menyebabkan kematian. Pemberian intervensi yang baik dan juga benar selama masa perawatan akan sangat membantu pasien untuk mencapai kesembuhan.

Perburukan kondisi yang parah atau stroke hemoragik hanya $20 \%$ penderita yang dapat hidup secara independent atau mandiri, sedangkan 40\% kasus meninggal dalam 30 hari dan sekitar separuhnya akan meninggal dalam 48 jam.(16) Saat awal masuk rumah sakit baik pada pasien stroke hemoragik maupun stroke iskemik keduanya memiliki ketergantungan total atau skor kemandirian yang sangat rendah, setelah diberikan perawatan dan latihan yang 
tepat nilai ketergantungan pasien menjadi lebih baik dalam menjalani ADL, namum masih ditemukan lagi sebagian pasien yang mengalami penurunan nilai kemandirian dan sebagian lagi memiliki nilai kemandirian yang sama pada saat awal masuk rumah sakit.(4)

Hasil uji statistik Spearman rank, jenis stroke terhadap kemandirian ADL pada penderita stroke di UPT. RSUD Undata Provinsi Sulawesi Tengah yaitu $p$-value $=0,524$,

karena nilai $p$-value $>0,05$ maka artinya tidak terdapat hubungan signifikan antara variabel jenis stroke terhadap kemandirian ADL pada pasien stroke di UPT. RSUD Undata Provinsi Sulawesi Tengah yang dikarenakan ditemukan sebagian besar responden dengan jenis stroke iskemik tetapi tidak mandiri dalam melakukan ADL, hal ini dikarenakan dalam menghitung ADL tidak hanya didasarkan pada domain jenis stroke tetapi juga melihat kondisi psikologi serta lingkungan sosial pasien, jika keadaan psikologi responden baik serta lingkungan sosial yang tercipta nyaman maka akan meningkatkan nilai kemandirian pasien dalam melakukan ADL. Banyaknya komplikasi yang diderita pasien juga akan mempengaruhi tingkat keparahan stroke sehingga untuk mengukur kemandirian ADL tidak hanya berdasarkan pada jenis stroke yang diderita. Analisis berdasarkan kuat hubungan dengan nilai 0,077 maka dapat dikatakan terjadi hubungan yang sangat kuat antara jenis stroke terhadap kemandirian ADL, dan analisis berdasarkan arah hubungan menunjukkan nilai positif, maka hubungan kedua variabel dikatakan searah yang berarti jika variabel jenis stroke meningkat maka variabel kemandirian ADL juga meningkat.

Hasil penelitian ini sejalan dengan Pei L, Zang XY, Wang Y, Chai QW, Wang JY, Sun CY, et al, yang menyatakan tidak adanya hubungan yang signifikan antara jenis stroke terhadap kemandirian ADL. Faktor yang memiliki hubungan sangat kuat yaitu status tinggal dengan keluarga atau tidak, kepercayaan diri, bantuan dan dukungan keluarga sangat mendorong pasien baik dari segi psikologi maupun fisik pasien yang dapat membantu meningkatkan nilai kemandirian dalam melakukan ADL.(17)

Pasca terserang stroke pasien akan mengalami bergantung kepada seseorang dalam melakukan aktivitas sehingga pasien tidak dapat melakukan aktivitas sehari-hari secara mandiri, oleh karena itu dibutuhkan motivasi dan dorongan diri dari pasien pasca stroke dan dukungan keluarga untuk mempercepat proses pemulihannya. Fungsi fisik merupakan domain penting dalam melakukan aktivitas secara mandiri pada pasien pasca stroke, kemudian diikuti oleh beberapa domain yaitu fungsi peran dan psikologis. Fungsi peran yang dimaksud yaitu dimana pasien stroke merasa tidak lagi dapat menjalankan perannya dalam 
keluarga seperti mengasuh anak dan pencari nafkah, kamudian pada faktor psikologis yaitu dimana pasien mengalami kesulitan dalam mengingat yang dapat mengganggu kondisi pasien dan juga ketika pasien tidak dapat menahan emosi atau kehilangan kesabaran atas beban yang ditanggungnya(18)

Hasil penelitian ini juga sejalan dengan penelitian yang dilakukan Fandri S, Utomo W, Dewi AP yang mengatakan bahwa tidak ada hubungan yang signifikan antara jenis stroke dengan kemandirian ADL. Pasien yang memiliki komplikasi penyakit akan memiliki tingkat ketergantungan yang tinggi dalam melakukan aktivitas dibandingkan dengan yang tidak memiliki komplikasi. Pasien yang memiliki komplikasi penyakit pengobatan tidak hanya berfokus pada penyakit stroke saja sehingga akan mempengaruhi kecepatan kesembuhan dan juga bila komplikasi penyakit tidak diobati dapat pula memperburuk keadaan stroke, sehingga kemandirian dalam ADL tidak hanya dilihat dari jenis strokenya saja tetapi juga dari komplikasi yang diderita pasien.(19)

Komplikasi pada pasien stroke banyak terjadi pada lansia, tingkat kerusakan motorik awal yang terjadi pada pasien stroke juga mempengaruhi terjadinya komplikasi. Pasien stroke dengan komplikasi terbanyak menunjukkan status fungsional tubuh yang buruk tidak hanya pada saat keluar rumah sakit, tetapi juga sampai 12 bulan setelah serangan stroke terjadi. Tercatat bahwa pasien stroke dengan komplikasi hipertensi, pneumonia, infeksi saluran kencing, penyakit jantung dan juga depresi memiliki skor ketergantungan yang sangat tinggi. (20)

\section{KESIMPULAN DAN SARAN}

Berdasarkan hasil penelitian diatas maka peneliti mengambil kesimpulan bahwa depresi dapat sangat mempengaruhi kondisi seseorang terhadap minat untuk melakukan sesuatu, depresi pada pasien stroke akibat dampak buruk perubahan fungsi tubuh mengakibatkan pasien merasa terpuruk dan tidak berdaya sehingga merasa tidak memiliki motivasi untuk menjalani hidup yang mendorong pasien menjadi tidak ingin berlatih pada masa rehabilitasi. Dukungan keluarga yang bernilai positif juga akan sangat membantu pasien pasca stroke untuk melewati masa-masa terpuruknya, banyaknya dukungan yang diberikan oleh keluarga akan membuat pasien berpikir bahwa dirinya tidak sendirian dan dapat membantu pasien menumbuhkan semangat berlatih. 


\section{DAFTAR PUSTAKA}

1. WHO. Top 10 causes of death. 2018.

2. Halawa F, Buulolo P budi, Gulo MA, Dachi PK, Nurhayati EL. Hubungan motivasi keluarga dengan efikasi diri. J Keperawatan. 2019;9(2).

3. Lindsay MP, Norrving B, Sacco RL, Brainin M, Hacke W, Martins S, et al. World Stroke Organization (WSO): Global Stroke Fact Sheet 2019. Int J Stroke. 2019 Oct 1;14(8):806-17.

4. Chayati N, Putranti DP, Firmawati E. Perkembangan dan Faktor-faktor yang

5. Memengaruhi Tingkat Kemandirian Pasien Strok Selama Rawat Inap di Yogyakarta berdasar atas Skor Modifikasi Indeks Barthel. Maj Kedokt Bandung. 2018;50(4):208-14.

6. Mayasari D, Imanto M, Larasati T, Ningtiyas IF. Hubungan Dukungan Keluarga dengan Tingkat Kemandirian dalam Activity Daily Living pada Pasien Pasca Stroke di Poliklinik Syaraf RSUD Dr . H . Abdul Moeloek Bandar Lampung Correlation of Family Support with The Independence of Activity Daily Living in Post. J Agromedicine. 2019;6(2):277-82.

7. Hanum P, Lubis R. Hubungan Karakteristik dan Dukungan Keluarga Lansia dengan Kejadian Stroke pada Lansia Hipertensi di Rumah Sakit Umum Pusat Haji Adam Malik Medan (Support from the Elderly Families, Stroke in the Elderly with Hypertension) Jumantik. 2018;3(1):72-88.

8. Dinas Kesehatan Sulawesi Tengah 2018. Profil kesehatan Provinsi Sulawesi tengah Tahun 2018. 2018. 1-222 p.

9. Alchuriyah S, Wahjuni CU. Faktor Risiko Kejadian Stroke Usia Muda Pada Pasien Rumah Sakit Brawijaya Surabaya. Fakt Risiko Kejadian Stroke Usia Muda Pada Pasien Rumah Sakit Brawijaya Surabaya. 2016;4(1):62-73.

10. Chemerinski E, Robinson RG, Kosier JT. Improved recovery in activities of daily living associated with remission of poststroke depression. Stroke. 2017;32(1):113-7.

11. Haghgoo HA, Pazuki ES, Hosseini AS, Rassafiani M. Depression, activities of daily living and quality of life in patients with stroke. J Neurol Sci [Internet]. 2016;328(1):8791.

12. Tatali AJ, Kundre R, Studi P, Keperawatan I, Kedokteran F, Sam U, et al. Hubungan Dukungan Keluarga Dengan Tingkat Kemandirian Activity Daily Living (Adl) Pada Pasien Pasca Stroke Di Poliklinik Neurologi Rsu Gmim Pancaran Kasih Manado. J Keperawatan. 2018;6(1).

13. Karunia. E. Hubungan antara dukungan keluarga dengan kemandirian Activity of Daily Living Pascastroke. J Berk Epidemiol. 2016;4(2):213-24.

14. Cross CJ, Nguyen AW, Chatters LM, Taylor RJ. Instrumental Social Support Exchanges in African American Extended Families. J Fam Issues. 2018;39(13):3535-63.

15. Kaur H, Kaur H, Venkateashan M. Factors determining family support and quality of life of elderly population. Int J Med Sci Public Heal. 2016;4(8):1049.

16. Mant J, Carter J, Wade DT, Winner S. Family support for stroke: a randomised controlled trial. Lancet. 2016;356(9232):808-13.

17. Darotin R, Nurdiana, Nasution TH. Analisis Faktor Prediktor Mortalitas Stroke Hemoragik di Rumah Sakit Daerah dr Soebandi Jember. NurseLine J. 2017;2(2):9.

18. Pei L, Zang XY, Wang Y, Chai QW, Wang JY, Sun CY, et al. Factors associated with activities of daily living among the disabled elders with stroke. Int $J$ Nurs Sci. 2016;3(1):29-34.

19. Linggi EB, Alfani K, Lembang M. Hubungan Activity Daily Living (ADL) Dengan 
Kualitas Hidup Pasien Pasca Stroke Di Ruang Fisioterapi RSUP.DR.Wahidin Sudirohusodo Makasar. J Ilm Kesehat Diagnosis Vol. 2018;12(6):675-80.

20. Fandri S-., Utomo W-., Dewi AP. Perbedaan Status Fungsional Pasien Stroke Saat Masuk dan Keluar Ruang Rawat Inap RSUD Arifin Achmad. J Online Mhs Progr Stud Ilmu Keperawatan Univ Riau. 2017;1-8.

21. Kim B-R, Lee J, Sohn MK, Kim DY, Lee S-G, Shin Y-I, et al. Risk Factors and

22. Functional Impact of Medical Complications in Stroke. Ann Rehabil Med. 2017/10/31. 2017 Oct;41(5):753-60. 